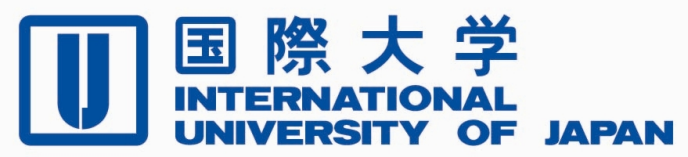

Economics \& Management Series

EMS-2012-10

\title{
Real options approach to renewable energy invest- ments in Mongolia
}

\author{
Neal Detert \\ SusDev Solutions Pte Ltd. \\ Koji Kotani \\ International University of Japan
}

August 2012

IUJ Research Institute

International University of Japan

These working papers are preliminary research documents published by the IUJ research institute. To facilitate prompt distribution, they have not been formally reviewed and edited. They are circulated in order to stimulate discussion and critical comment and may be revised. The views and interpretations expressed in these papers are those of the author(s). It is expected that the working papers will be published in some other form. 


\title{
Real options approach to renewable energy investments in Mongolia
}

\author{
Neal Detert* $\quad$ Koji Kotani ${ }^{\dagger}$
}

August 27, 2012

\begin{abstract}
Many developing nations are in transition from non-renewable to renewable energy in electricity generation. This research analyzes this type of changing investment environment for renewable energy projects such as wind farms and solar-thermal plants with the application of real options theory. The main intent is to explore the potential and to provide further insights for such a transition in developing economies through studying the case of Mongolia under coal price uncertainty. To evaluate the comparative attractiveness of either continuing to use non-renewable (coal-based) infrastructure or switching to renewable energy, we formulate social revenue functions for the two environments under the assumptions that coal-based operations generate negative externalities and renewable energy is externality-free. Framing the problem as a type of real options, we arrive at the optimal trigger prices of coal for switching technologies. With this analytical framework, we further pose some possible scenarios with respect to electricity price as well as negative externality valuation, and characterize when renewable energy investments become attractive. In sharp contrast to conventional wisdom in real options theory, we identify some situations where option values for switching technologies become negative in some price domains, and welfare losses are incurred. Overall, the result raises the possible risks in developing nations that waiting to switch energy sources yields huge losses under input price uncertainty. To avoid such a case in Mongolia, the government should remove coal subsidies and increase electricity prices or switch to renewable energy earlier rather than holding the option to wait, especially when people are willing to pay more for the removal of negative externalities.
\end{abstract}

Key Words: Alternative energy investment, real options in discrete time, coal prices, stochastic process

JEL Classification: C61, G11, O13, Q32, Q42

\footnotetext{
*Managing Director, SusDev Solutions Pte Ltd, 2 Flora Dr., 06-15 Carissa Park 507025 Singapore.

${ }^{\dagger}$ Associate Professor, Graduate School of International Relations, International University of Japan, 777 Kokusai-cho, Minami-Uonuma, Niigata 949-7277 Japan.
} 


\section{Introduction}

In this paper, we examine the optimal decision timing for alternative energy investments under situations of uncertainty using a real options approach. This approach is similar to methods used in finance for valuing American call options and the framework applied in this paper follows the concepts set forth by Dixit and Pindyck (1994), Smith and McCardle (1999) and Schwartz and Trigeorgis (2004). More specifically, this research frames an energy investment decision in Mongolia as a real options problem in discrete time. In line with Boyarchenko and Levendorskii (2007), we take the view that a discrete time approach could be more practical than one in continuous time for some specific cases.

Though existing literature predominantly analyzes decision making in a continuous time setting (see Insley (2002), Metcalf and Hasset (1995), and others), it is our belief that modeling in discrete time more accurately reflects the decision-making process of policy makers and public institutions who are especially concerned with infrastructure investment decisions in resource and environmental problems. This is due to the fact that public decisions on infrastructure investments tend to be updated on a yearly basis. Therefore, the analyses of optimal timing strategies and policies undertaken in this study are conducted in discrete time in order to best approximate the appropriate decision making environment (See, e.g., Boyarchenko and Levendorskii (2007), Plantinga (1998), Bosetti et al. (2004), and Haight and Holmes (1991)).

As a result of the global financial crisis and corresponding economic slowdown, fossil fuel prices have eased from the record highs set in 2007. However, as global economic activities pick up, particularly in China, India, and other emerging economies, there has been renewed debate among policy makers and business leaders about the continued viability of, and risks associated with, maintaining fossil fuel-based energy infrastructures. This debate is centered on issues of supply chain security, national security, price volatility, and other negative useassociated externalities such as air pollution and water usage. Increasingly, the potential for new investments in alternative energy technologies is addressed as a solution to these issues, 
particularly when investments in infrastructure and physical assets make up a large portion of nations' fiscal stimulus packages and budgets.

The broad objectives of this research are to bring the discussion to the viewpoint of a developing economy and to depict the economic feasibility of various energy sector investment strategies as they relate to the above affairs. Another of these broad objectives is to initially remove the socially and politically polarizing aspects of the debate, such as climate change, and instead focus on fossil fuels as a finite source of energy in an industry that has technologically matured (Sheer (2007)). The specific objective of this research is to evaluate various energy sector investment options in Mongolia under situations of uncertainty through the application of financial options pricing theory to real investments.

It is inevitable that global reserves of fossil fuels will eventually be exhausted, especially at the currently increasing and unsustainable rate of use. According to Hermann Scheer, the aggressive push for economic development has led to "the growing dependence of more and more countries on fewer and fewer production sources" (Sheer (2007), page 37). As these finite resources become scarcer and global competition intensifies, prices are bound to continue to accelerate their upward trend with increasing volatility and uncertainty if demand maintains its current path. Therefore, for this research, price levels of coal are used as the stochastic variable representing the uncertainty in the model.

The changing economically feasible investment environment due to this uncertainty over time and at different coal price ranges is included with energy prices, quantities of energy and coal produced and consumed, cost of energy production, and externalities. These parameters are used to create social welfare, or revenue, functions for both pre- and post-renewable energy technologies investment environments. The cost of energy production is broken into two categories, being the cost related to using coal and the cost for investing in, and using, a combination system of $50 \%$ wind generation and $50 \%$ solar-thermal generation with the included ability to store energy generated from both systems for up to seven hours in nongenerating periods (Kaltzchmitt et al. (2007)). 
The factors composing the externalities are national security, supply chain security, air quality, and water usage. To value these opportunity costs, various amounts are arbitrarily assigned in the model to provide a scale that realistically represents society's willingness to pay for their reduction or elimination. After adequately assessing the necessary parameters, the expected net present value of social revenue is then dynamically optimized through a real options approach to identify the optimal strategy as well as option values for the renewable energy investment.

The optimal strategy in our problem is characterized by the trigger prices, which are thresholds to define the optimal action of whether to make the investment or not. More specifically, the optimal strategy becomes a trigger strategy in which if the current price of coal is larger than the trigger price, investments in alternative energy should be made, otherwise not. In fact, this is the price at which it becomes the most economically efficient to invest in renewable energy as opposed to continued use of a non-renewable (coal-based) infrastructure. The valuation of these investments using options theory comes by expanding this model to include the chance for policy makers to wait before making the investment decision. This option to wait allows for increased information and therefore it is believed that it adds positive value to the investment (Dixit and Pindyck (1994)).

Contrary to the above statement, this paper addresses a novel and unique situation where the value of waiting, or simply the 'option value', can be negative in some domain of coal prices and leads to welfare losses. With this unique feature in mind, we further seek to characterize the situations where (i) this type of event occurs through analyzing the case of Mongolia and (ii) renewable energy becomes more attractive as an investment option. For these purposes, we pose several scenarios with respect to electricity prices and negative externality valuation. Electricity and coal input prices in Mongolia are currently set and subsidized by government authorities, whereas negative externality valuation represents how much Mongolian people are willing to pay for the removal of externalities generated by the coal-based energy operation. 
Our analysis suggests that negative option values can arise either when the electricity price is sufficiently low or when negative externalities are given a sufficiently high value. Furthermore, we identify that a change in the value of electricity prices and negative externalities significantly affects the optimal decision timing and value of the investment. Both the option value of investment and trigger price decline as the value of externalities rises. This implies that optimal investment timing tends to be earlier as the value of negative externalities becomes higher. On the other hand, the value of investment rises and trigger prices decline when electricity prices increase, which also implies that the optimal investment timing becomes sooner as the electricity prices rise.

Overall, these results imply that switching from non-renewable to renewable energy may potentially cause welfare losses in a situation of market uncertainty. To avoid such a case in Mongolia, the government should increase electricity prices (which are currently set at $\approx 51$ togrog $(\mathrm{TG})$ per $\mathrm{KwH})$ since the current level is likely to result in negative net present values and negative option values. Otherwise, the Mongolian government should switch to renewable energy earlier rather than waiting, especially if the domestic population is considered to have a willingness to pay for the removal of negative externality.

To the best of our knowledge, this study is the first that frames the energy switching problem from non-renewable to renewable as a type of real options, and characterizes the corresponding important determinants for the optimal strategy. It is our belief that the series of analyses and conclusions made in this study for Mongolia provides further insights on more general problems of energy switching. Many other developing nations currently face similar situations and problems, and this work raises the potential risks and countermeasures of such investment opportunities from non-renewable to renewable energy that can be seen all over the world.

In the next section we provide a background discussion on the Mongolian economy, Mongolia's energy and mining sectors, and coal price determination as applied in this paper. Section 3 presents the economic model and methodologies, followed by the decision anal- 
ysis under various investment scenarios in section 4. The concluding comments and final discussion are provided in section 5 .

\section{The Mongolian Economy, Energy, and Mining Sec- tors}

\subsection{Key economic indicators}

Many developing and emerging economies today are moving toward greater openness through trade liberalization policies and are shifting from centrally controlled systems to privatized, free-market economies. During the early 1990's, Mongolia began its shift from a Sovietstyled socialist system to a more liberalized, free-market economy (Economist Intelligence Unit (2007)). According to International Monetary Fund (IMF) and Economist Intelligence Unit (EIU) Country Reports, Mongolia has been progressing rapidly in the privatization of government services, in market economy development, and in financial reforms, which have contributed to strong economic growth over the past decade.

The country data and key economic indicators for Mongolia from these reports are summarized in table 1. From 1994 to 2005, Mongolia averaged 4.33\% real GDP growth, peaking at $10.8 \%$ in 2004 and averaging $7.97 \%$ growth in the final three years (International Monetary Fund (2007) and International Monetary Fund (2002)). The structure of the economy is based heavily on the mining and agricultural sectors, though the service industry also made exceptional inroads from 2000 to 2005, with the wholesale and retail trade sector making up $25.9 \%$ of real GDP in 2005. Though both the agriculture and service sectors have significant roles in the Mongolian economy, the solid economic growth realized recently has been primarily driven through exports by the non-oil mineral production sector, which realized an average of $22.6 \%$ industry growth in 2004 and 2005 (International Monetary Fund (2007) and Economist Intelligence Unit (2007)). In 2005, mineral exports accounted for $36.6 \%$ of 
Table 1: Mongolia Key Economic Indicators

\begin{tabular}{|c|c|c|c|c|c|c|c|c|c|}
\hline \multirow{2}{*}{\multicolumn{2}{|c|}{$\begin{array}{l}\text { GDP Growth Rate } \\
(\% \text { per annum })\end{array}$}} & 2001 & 2002 & 2003 & 2004 & 2005 & 2006 & 2007 & 2008 \\
\hline & & 1.1 & 4.7 & 7.0 & 10.6 & 7.3 & 8.6 & 10.2 & 8.9 \\
\hline \multicolumn{2}{|l|}{$\begin{array}{l}\text { GDP per capita } \\
\text { (Current } 1000 \mathrm{TG})\end{array}$} & 457.2 & 498.7 & 644.1 & 850.6 & 1085.8 & 1434.3 & 1742.3 & 2287.4 \\
\hline \multirow{5}{*}{$\begin{array}{l}\text { Structure of GDP } \\
(\% \text { of GDP })\end{array}$} & Agriculture & 24.9 & 20.5 & 20.7 & 22.2 & 21.9 & 19.5 & 20.5 & 18.8 \\
\hline & Mining & 9.0 & 10.2 & 11.7 & 17.2 & 22.1 & 30.0 & 29.1 & 27.8 \\
\hline & Non-mining & 10.0 & 8.8 & 10.4 & 8.7 & 8.3 & 7.6 & 8.3 & 8.1 \\
\hline & Electricity, Gas \& Water & 3.0 & 3.8 & 3.7 & 3.3 & 3.2 & 2.8 & 2.3 & 2.2 \\
\hline & Services & 53.1 & 56.7 & 53.6 & 48.6 & 44.6 & 40.1 & 39.8 & 43.1 \\
\hline \multicolumn{2}{|c|}{$\begin{array}{l}\text { Consumer Price Index Change } \\
(\% \text { per annum, } 2000 \text { Base) }\end{array}$} & 8.0 & 1.0 & 3.4 & 8.3 & 12.1 & 4.8 & 9.6 & 28.0 \\
\hline \multicolumn{2}{|c|}{$\begin{array}{l}\text { Unemployment Rate } \\
(\%)\end{array}$} & 4.6 & 3.4 & 3.5 & 3.6 & 3.3 & 3.2 & 2.8 & 2.8 \\
\hline \multicolumn{10}{|c|}{ Sources: IMF (2007, 2009), EIU (2009), NSO (2009), World Bank (2009), and ADB (2009) } \\
\hline \multirow{2}{*}{\multicolumn{2}{|c|}{\begin{tabular}{|l} 
Exchange Rates \\
January 1,2010
\end{tabular}}} & Euro $(€)$ & USD (\$) & JPY (¥) & & & & & \\
\hline & & $2,054.31$ & $1,430.00$ & 15.45 & & & & & \\
\hline
\end{tabular}

GDP and $70.7 \%$ of total exports (International Monetary Fund (2007)).

\section{$2.2 \quad$ Energy and mining sectors}

The rapid market liberalization and industrialization in major emerging countries like China, India, and Brazil, as well as the intense development throughout the rest of the world, has resulted in a rush to secure goods and natural resources, steeply increasing demand and prices while straining supplies. The rise in prices for oil and gas has been caused by this combination of increased demand and restricted supply and has resulted in a shift toward cheaper commodities such as coal (DATAMONITOR (2007)).

This situation has brought about emerging country energy sectors that are increasingly dependent on coal for their generative capacity. According to World Coal Institute (2005), the use of coal for energy generation globally has increased more than any other fuel source. This is particularly the case in Asia, where India and China account for $68 \%$ of the increase in 
Figure 1: Mongolian Electricity Generation

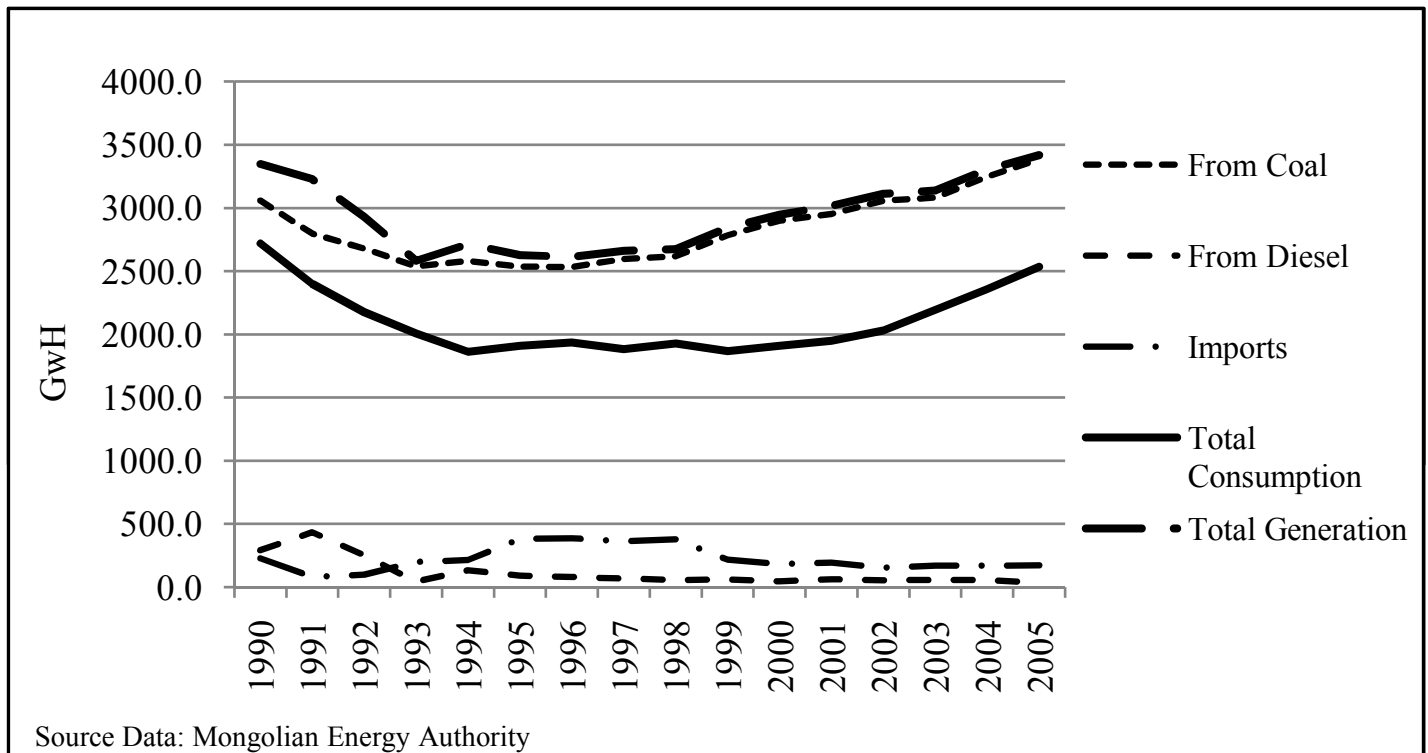

coal demand (World Coal Institute (2005)). It is also predicted that in the next three decades global energy demand will rise by approximately $60 \%$, with the majority of that increase being attributed to developing countries' economic growth (World Coal Institute (2005)). Mongolia, as the proxy for smaller developing countries in this report, falls within this rank of rapidly industrializing and liberalizing economies whose energy sectors are almost wholly dependent on coal for their power generation.

According to disclosed electricity generation data obtained from the Mongolian Energy Authority, from 1990 to 2005, thermally generated electricity from coal accounted for an average of $96.2 \%$ of total domestic generation, with electricity from diesel generators running a distant second with approximately 3.8\%. Mongolia also has 3.5 MW worth of hydroelectric generation capacity installed, but the data for total amounts of electricity generated annually from this source was not disclosed by Mongolian Energy Authority (2006). Figure 1 details the distribution of electricity generation and consumption within Mongolia from 1990 to 2005.

In recent years, the Mongolian government has been working to restructure and priva- 
tize its energy and mining industries. According to Mr. Russell Brown, who was advising the Mongolian government on privatization policies under the auspices of a USAID funded project, the process of privatizing mining industries is underway and will see strong progress over the coming years (Brown (2008)). The energy sector, however, is currently still heavily subsidized and accounted for an average of $48.1 \%$ of total subsidies from 1994 to 2005 (International Monetary Fund (2007)). From 1996 to 2005, the Mongolian government privatized a total of 864 state-owned enterprises with 7 of those being in the minerals sector (Brown (2008); International Monetary Fund $(2007,2002)$ ). Competition injected through energy and mining sector privatizations will allow the government to decrease the energy subsidy factor and increase the industries' efficiency. Additionally, trade liberalization measures will force domestic producers to compete internationally as the domestic market prices will be expected to rise to their global equivalents (Brown (2008)).

\subsection{Coal price determination}

Until recently, the Mongolian government has maintained price-setting and subsidization policies for energy and raw commodities, including coal. Resulting from these past policies, the domestic price for coal in Mongolia cannot be assumed to vary stochastically. As we described in the previous sector, with Mongolia continuing to privatize and induce competition in the mining and energy sectors, prices are expected to reach globally competitive levels. The prices of other natural resources such as oil are widely known to follow global market trends, but until recently, coal has been a far more protected and price-regulated commodity (Ellerman (1995)). Ellerman (1995) and Warell (2005) examine this shifting environment and lay the case for the existence of global and regional prices of coal.

Ellerman (1995) makes the claim that world market prices for coal today are mostly dominated by the influence of the U.S. economy on the world economy. Warell (2005) takes this claim further to describe the interactions of regional coal sources and regional economic influencers. From this perspective, in the Asia-Pacific, South-East Asia, and Central Asia 
regions, the economies with the greatest influence are Japan and China, with Australia providing the majority of coal imported by Japan, China, India, and the rest of the region. World Coal Institute (2005) also divides the international coal market regionally into the Atlantic and the Pacific.

The Pacific market for coal makes up $60 \%$ of the world market and comprises both developing and industrialized countries that are predominantly coal importers, such as Japan, Korea, and Taiwan (World Coal Institute (2005)). As the majority of exported Mongolian coal is bound for the neighboring Chinese or Japanese market, applying either Chinese or Japanese coal prices would be a good indicator for the price level domestically consumed Mongolian coal could be expected to reach. However, because of data limitations for the Chinese coal market, we use Japan as the regional coal price setter. Japan imports nearly $100 \%$ of its coal products (Japanese Statistic Bureau (2008)) and, therefore, Japan's import

prices are a good proxy for the regional coal prices that the Mongolian market would be expected to attain in a fully privatized and liberalized environment (Warell (2005)).

Figure 2 details this regional coal price pathway over time based on Japanese coal import price data. As our analysis is focused on the Mongolian economy and investment environment, we have converted the price values into the local Mongolian currency, the Togrog (TG). From this picture, we can get an idea of the stochastic processes that regional coal prices will be expected to follow. In the next section, we define the stochastic price processes to be tested for and applied in our dynamic optimization.

\section{Parameter Estimation and Model Specification}

\subsection{Stochastic price processes}

The stochastic characteristics of fossil fuel prices have been a subject of much empirical concentration and theorization, especially in regard to oil. We use techniques applied by Haight and Holmes (1991), Metcalf and Hasset (1995), Dixit and Pindyck (1994), and Insley 
Figure 2: Real Price of Coal

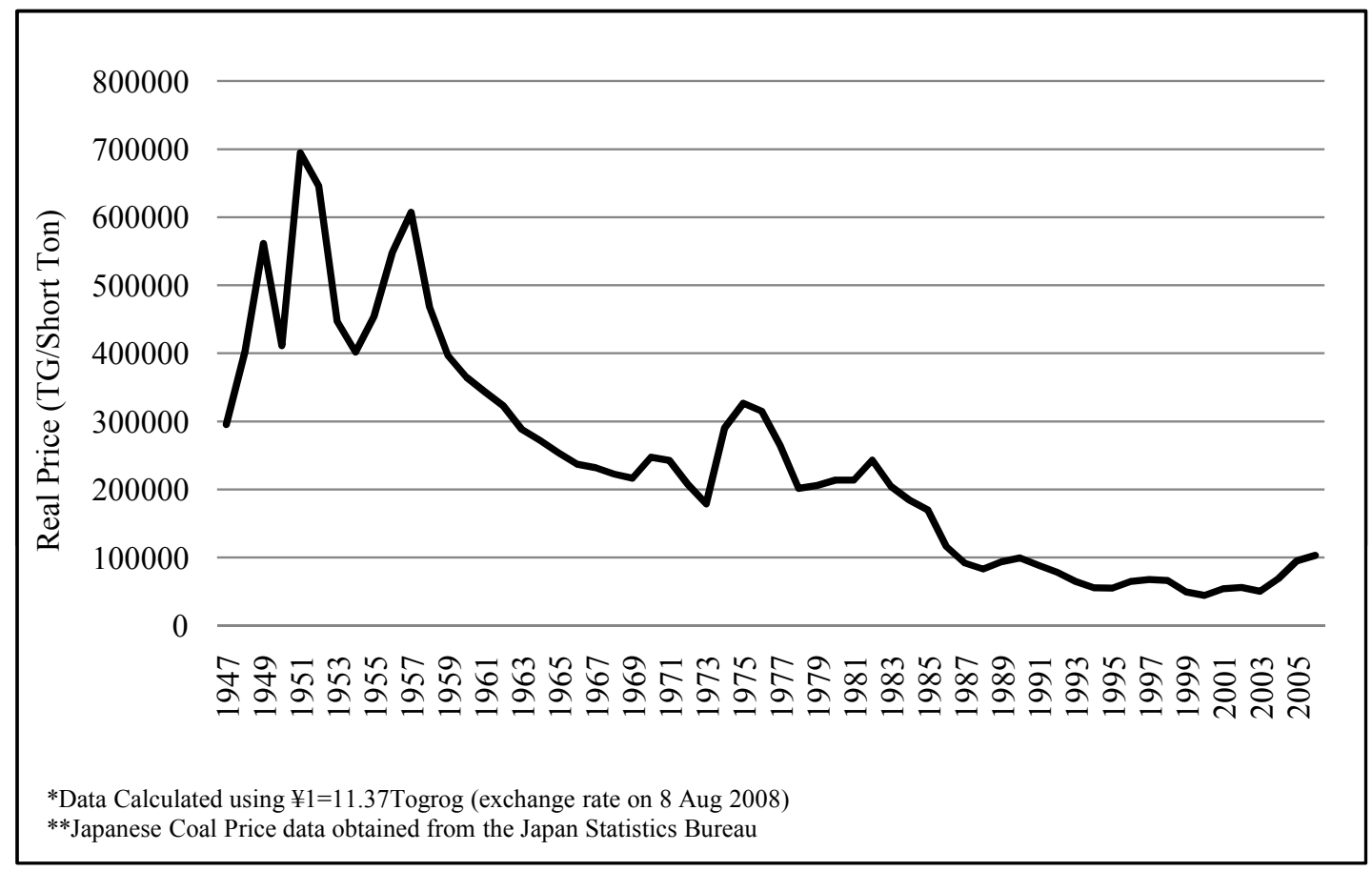

(2002) to determine the basic potential stochastic processes of coal prices. These works draw distinctions between geometric Brownian motion (GBM) and geometric mean reverting (MR) processes, and discretizes these continuous stochastic processes for estimating parameters. In this analysis, we apply both methods of estimation with the same discretization schemes and make the necessary comparisons between the discretized versions of GBM and MR.

In assuming the price of coal, $P$, follows a process of geometric Brownian motion with a drift, the literature presents the stochastic price process as

$$
d P=\alpha P d t+\sigma P d z
$$

where $\alpha$ and $\sigma$ are constants representing the rates of drift and variance, respectively, and $d z$ is the increment of a Wiener process in continuous time as defined by Dixit and Pindyck 
(1994). Here, the Wiener process is designated by

$$
d z=\varepsilon_{t} \sqrt{d t}
$$

where $\varepsilon_{t}$ is standard normally distributed such that $\varepsilon_{t} \sim N(0,1)$. For a more detailed explanation on GBM and Weiner processes in continuous time, refer to Dixit and Pindyck (1994). For our analysis, we apply a discretized version of the GBM process. To test the existence of a potential GBM process we follow the work of Insley (2002) in creating an augmented Dickey Fuller test. Under the assumptions of Ito's Lemma we know that if the price of coal follows GBM, then $F(P)=\ln P$ follows a simple Brownian motion with drift as

$$
d F=\left(\alpha-\frac{1}{2} \sigma^{2}\right) d t+\sigma d z
$$

For examining the stochasticity under discrete time and testing for a GBM process we must first set the function as

$$
p_{t+1}-p_{t}=\left(\alpha-\frac{1}{2} \sigma^{2}\right) \Delta t+\sigma \varepsilon_{t} \sqrt{\Delta t}
$$

where $p_{t}$ is the natural logarithm of $P_{t}$. To run the augmented Dickey Fuller unit root test, we set the regression equation such that

$$
p_{t+1}-p_{t}=c(1)+c(2) p_{t}+\sum_{j=1}^{L} \lambda_{j} \Delta y_{t-j}+e_{t}
$$

where $c(1)=\left(\alpha-\frac{1}{2} \sigma^{2}\right) \Delta t, e_{t}=\sigma \varepsilon_{t} \sqrt{\Delta t}$, and $L$ is the number of lags. ${ }^{1}$

Table 2 shows the results of the augmented Dickey Fuller unit root test and it implies that the null hypothesis of a unit root cannot be rejected at significance levels of $10 \%, 5 \%$ or $1 \%$. Therefore, the analysis will proceed with the possibility that coal prices follow a discretized version of GBM. After determining the existence of a unit root in the price of coal, we move to estimate the drift and variance rates $\alpha$ and $\sigma$, respectively, Adhering to

\footnotetext{
${ }^{1}$ The lag length was chosen through experimentation following the procedure introduced in Enders (2004).
} 
Table 2: GBM Augmented Dickey Fuller Test on Coal Price

\begin{tabular}{|c|c|c|c|}
\hline \multicolumn{4}{|c|}{$\mathrm{H}_{0}: \quad p_{t}$ has a unit root } \\
\hline \multirow{2}{*}{\multicolumn{2}{|c|}{ Augmented Dickey-Fuller test statistic }} & t-Statistic & Prob.* \\
\hline & & -1.2081 & 0.6653 \\
\hline \multirow[t]{3}{*}{ Test critical values: } & $1 \%$ level & -3.5482 & \\
\hline & $5 \%$ level & -2.9126 & \\
\hline & $10 \%$ level & -2.5940 & \\
\hline Variable & Coefficient & & t-Statistic \\
\hline $\mathrm{c}(1)$ & 0.4399 & & 1.1515 \\
\hline $\mathrm{c}(2)$ & -0.0380 & & -1.2081 \\
\hline$\lambda_{1}$ & 0.1659 & & 1.2797 \\
\hline
\end{tabular}

Insley (2002), we use the maximum-likelihood estimates of $\alpha$ and $\sigma$. Assuming $P_{t}$ follows GBM, $\alpha=\mu+\left(\frac{1}{2}\right) s^{2}$, where $\sigma=s$ and $\mu$ and $s$ are the mean and standard deviation of $p_{t}-p_{t-1}$. In making the calculations, we arrive at $\alpha=0.000260$ and $\sigma=0.190246$, which will be applied to the real options analysis that follows.

The second method of defining the stochastic processes of coal prices in our model is through the discretized version of MR. Metcalf and Hasset (1995) detail the claim that though for some economic variables the drifting of the GBM process is accurate, but for others, such for minerals and other raw commodities, the prices tend to return to a mean. This is the characterization of mean reverting, where long-run prices move closely around the marginal costs of production (Dixit and Pindyck (1994)). According to Metcalf and Hasset (1995), the simplest of the mean reverting processes is called the geometric OrnsteinUhlenbeck process and is defined in continuous time as

$$
d P=\eta P(\bar{P}-P) d t+\sigma P d z
$$

After discretizing and simplifying, we arrive at

$$
\frac{P_{t}-P_{t-1}}{P_{t-1}}=c(1)+c(2) P_{t-1}+e_{t}
$$


Table 3: MR Estimates

\begin{tabular}{|cccc|}
\hline Variable & Coefficient & t-Statistic & Prob. \\
\hline $\mathrm{c}(1)$ & 0.0315 & 0.6601 & 0.5118 \\
$\mathrm{c}(2)$ & $-1.2716 \mathrm{E}-07$ & -0.7795 & 0.4389 \\
$P$ & 247391 & & \\
$\eta$ & $1.27 \mathrm{E}-07$ & & \\
$\sigma$ & 0.2044 & & \\
\hline
\end{tabular}

where $c(1)=\eta \bar{P} \Delta t, c(2)=-\eta \Delta t$, and $e_{t}=\sigma \sqrt{\Delta t \varepsilon_{t}}$. The estimates obtained by regressing equation (7) are listed in table 3 along with the parameter estimates for $\eta$, $\sigma$, and $\bar{P}$. Although table 3 shows $c(1)$ and $c(2)$ as insignificant, the analysis will be undertaken by assuming that coal prices follow MR processes with the estimated parameters for the purpose of comparision.

\subsection{Social revenue}

In this subsection, we define social revenue functions for the current and post-investment environments in each period. These functions represent the net benefit to society of using coal or alternative energy and are the points of determination for whether or not to proceed with the investment. The social revenue for continuing to use the coal-based energy infrastructure in each period is

$$
\pi_{C, t}=P_{E} Q_{E D} l-P_{C, t} Q_{C}-P_{E} Q_{E I}-D
$$

where $l=1-u$ is the percent efficiency with the electricity generation use and distribution loss parameter of $u, P_{E}$ is the price of electricity, and $Q_{E D}, Q_{C}$, and $Q_{E I}$ are the quantities of domestically produced electricity, coal consumed for electricity production, and electricity imported, respectively. $P_{C, t}$ is the stochastically varying price of coal and $D$ represents the externalities associated with the use of a coal-based infrastructure.

The value for $D$ will be arbitrarily assigned and varied to reveal the different amounts that Mongolian residents would be willing to pay for the removal or reduction of air pollution from 
burning coal, national and energy security under increased global demand for resources, and increased availability of usable water by not having resources tied up in coal-fired thermal power stations. Under the restrictions of our model, we are assuming that no technological options are available to affect $u$ or $D$ and that no additional capacity can be added to reduce the amount of energy imported or likewise increase consumptive efficiency. We make the assumption that the only option available is to switch technologies.

The social revenue in each period after making the technological switch to alternative energy is described by

$$
\pi_{A, t}=P_{E} Q_{E}-C_{A}
$$

where $C_{A}$ is the cost of operating the stated alternative technology. However, note that switching to alternative energy must incur a one-time fixed initial investment cost of $I_{A}$, which will be introduced later. These two social revenue functions are employed in identifying expected net present values of investment options, as well as in the algorithm of the real options approach along with the stochastic price variable.

\subsection{Monte Carlo simulations}

Now that we have obtained the parameter estimates for the stochastic price processes and defined the social revenue, we proceed with the Monte Carlo simulation to identify the expected net present values of using a coal-based infrastructure. The expected net present values in the terminal period must be specified and the Bellman equation applied backward to solve this investment problem, and such expected net present values cannot be analytically derived. The terminal period in this model is defined as the last period in which policy makers still have the ability to choose between coal and an alternative energy. After this terminal period, the option to invest in alternative energy will no longer be available and they must continue to use coal.

The net present value of using the coal-based energy infrastructure at the terminal period 
is represented by

$$
N P V_{C}=\sum_{t=0}^{T_{C}} P V_{C, t}=\sum_{t=0}^{T_{C}} \rho^{t}\left(P_{E} Q_{E D} l-P_{C, t} Q_{C}-P_{E} Q_{E I}-D\right)
$$

where $\rho$ represents the discount factor and is defined as $\rho=\frac{1}{(1+\gamma)}$, with $\gamma$ being the discount rate, $T_{C}$ the number of years the coal based infrastructure will effectively be used after the terminal period, and $P V_{C, t}=\rho^{t} \pi_{C, t}$ the present value of revenue with a coal-based energy. Our goal in the Monte Carlo simulations is to find the expected values represented by equation (10).

The next step is generating a vector of possible coal price realizations from $t=0$ to $t=T_{C}$ by using the stochastic processes estimated in our discretized versions of GBM and MR. These underlying price generating processes for GBM and MR used in this simulation are

$$
\begin{aligned}
& P_{C, t+1}=P_{C, t}+\alpha P_{C, t}+\sigma P_{C, t} \varepsilon_{t}, \quad \text { for } \mathrm{GBM} \\
& P_{C, t+1}=P_{C, t}+\eta P_{C, t}\left(\bar{P}-P_{C, t}\right)+\sigma P_{C, t} \epsilon_{t}, \quad \text { for } \mathrm{MR}
\end{aligned}
$$

where $\varepsilon_{t} \sim N(0,1)$. To reach the expected net present value for using coal at each of the terminal period price nodes the present values are summed according to $N P V_{C}=\sum_{t=0}^{T_{C}} P V_{C, t}$, where the present value in each period can be calculated using a vector of coal price realizations generated from the stochastic processes of equations (11) and (12). This process is repeated a sufficiently large number of $J$ times to approximate the expected net present value estimation at each price node $i$ by taking the average of $\mathbb{E}\left(N P V_{C, j}\right) \approx \frac{1}{J} \sum_{j=1}^{J} N P V_{C, j} \approx$ $\mathbb{E}\left[N P V_{C}\right]$. Finally, a series of the same procedures are taken to calculate the net present value at each terminal period price node ranging from the minimum $P_{C, 0}=0$ to the maximum $P_{C, 0}=1,000,000$ at steps of 1,000 .

Now that we have obtained the expected net present values for each price node in the terminal period, we are prepared to move into the dynamic optimization process and to 
frame our investment problem as an American-style option valuation. Using this method, decision makers are granted the ability to reevaluate the investment environment at any time between the initial and terminal periods.

\subsection{Real options approach in discrete time}

This final exercise in determining the optimal timing and the associated trigger prices for

alternative energy investments in Mongolia is centered on dynamic programming (Puterman (1994); Bertsekas (2001)). A social planner's problem for this energy investment is posed as the following optimal stopping under stochastic coal prices of a discretized GBM or MR. In other words, the optimal switching timing should be derived by solving the following problem of maximizing the expected net present value of social revenue:

$$
\sup _{0 \leq \tau \leq T+1} \mathbb{E}\left\{\sum_{0 \leq t<\tau} \rho^{t} \pi_{C, t}+\rho^{T} N P V_{C, T}\left(1-\mathbb{I}_{\{\tau \leq T\}}\right)\right\}+\left(\sum_{t=\tau}^{\tau+T_{A}} \rho^{t} \pi_{A}-\rho^{\tau} I_{A}\right) \mathbb{I}_{\{\tau \leq T\}}
$$

where $T$ is the length of time during which a social planner has an option to switch to alternative energy, $\tau$ is the period in which the investment for switching to alternative energy is made, $T_{A}$ is the number of years for which the alternative energy infrastructure will be used after making the investment, and $\mathbb{I}_{\{\tau \leq T\}}$ is an indicator function which becomes 1 with $\tau \leq T$ or is otherwise 0 . In this specification of the problem, a social planner is required to choose an optimal timing of $\tau$ to maximize the expected net present value of social revenues represented by equation (13).

The problem posed in equation (13) can be solved by backward induction through dynamic programming from the terminal period (Puterman (1994); Bertsekas (2001)). That is, optimal timing for switching should be evaluated based on the following Bellman equation at every period.

$$
V_{t}\left(P_{C, t}\right)=\max \left\{N P V_{A}, \pi_{C}+\rho \mathbb{E}\left(V_{t+1}\left(P_{C, t+1}\right) \mid P_{C, t}\right)\right\}
$$


and

$$
N P V_{A}=-I_{A}+\sum_{k=0}^{T_{A}} \rho^{k} \pi_{A}=\left(\frac{\rho-\rho^{T_{A}+1}}{1-\rho}\right) \pi_{A}-I_{A}
$$

where $N P V_{A}$ represent the net present value accrued from alternative (renewable) energy infrastructure, and $I_{A}$ is a fixed investment cost.

Working backward from the terminal to initial periods, the attractiveness of using a coalbased infrastructure or switching to alternative technologies is valued annually. This process represents the ability of the decision makers to re-evaluate the investment environment each year and adjust their investment decision accordingly. As was defined earlier, discretized versions of GBM and MR represent different theories of commodity price behavior. We created GBM and MR versions of the MATLAB program to generate $N P V_{C}$ via the Monte Carlo simulation and solve the optimal stopping problem posed in equation (13). ${ }^{2}$

The optimal timing for switching to alternative energy is characterized as a trigger strategy because for every period $t$, there exists some threshold $P_{C, t}^{S}$ such that switching to alternative energy is optimal if $P_{C, t}>P_{C, t}^{S}$. In other words, our MATLAB codes yield the optimal trigger strategy with threshold levels of $P_{C, t}^{S}$ that maximizes the expected net present values of social revenues in equation (13).

\section{Trigger prices under real options approaches}

\subsection{Baseline values}

In determining an adequate set of baseline parameter values, we used data gathered from the Mongolian Energy Authority (2006), International Monetary Fund (2007), Economist Intelligence Unit (2007), ADB information (Enebish (2004)), and National Renewable Energy Laboratory resources (Elliot et al. (2001)). From these sources we determined domestic energy production, domestic energy consumption, energy imported, and coal consumption

\footnotetext{
${ }^{2}$ The algorithm adopted for the solution to this optimal stopping problem follows the value iteration methods introduced in Judd (1998).
} 
for the purpose of energy generation. Also, through Enebish (2004) and Elliot et al. (2001) we were able to categorize Mongolia in regard to its endowment of land suitable for solar and wind collection. As stated by these authors, Mongolia has a unique climate and environment for both solar and wind power generation, characterized by an average of 220 to 260 clear, sunny days a year and a multitude of sites with average annual wind speeds from 7 to 10 meters per second. Using values obtained from these sources, we estimated the appropriate social revenue parameter values for using coal and the alternative energy combination as per the system descriptions outlined in Kaltzchmitt et al. (2007).

Taking these assessments into account, we elected for system settings according to maximized technological advantages and to mid-range generation sites for both wind and solar power collection as defined by Kaltzchmitt et al. (2007). We chose site estimations lower than those reported in the literature in order to describe a realistic minimum potential situation. Additionally, the cost estimates included storage system technologies that would provide for seven hours worth of usage in non-generating periods. This purpose was again to provide the most realistic estimations for the potentially true cost of converting to a solely wind and solar-thermal energy infrastructure. The results of these calculations for the social revenue baseline parameter values are detailed in table 4 .

The value of coal-use related externalities $(D)$ for the baseline scenario was set to zero to provide an initial estimate according to standard options-based profit valuation methods and for comparison in later scenarios. Also, the time lengths for both the Monte Carlo simulation $T_{A}$ and the dynamic optimization process $T$ were set to a middle range of 50 years. In this context, that would represent a situation where policy-makers were given 50 years to decide whether or not to make the investment with no choice given after the terminal year. That choice is then valued within another 50 year context, representing the lifetime of the investment. These values will also be varied in later scenarios to show the most appropriately realistic investment environments. Aside from estimations of the price behavior-specific variables of GBM and MR defined in section 3, all of the other input 
Table 4: Baseline scenario parameter estimates

\begin{tabular}{|lc|}
\hline$Q_{E}=$ & $3559.84 \mathrm{Mio} \mathrm{KwH} / \mathrm{a}$ \\
$Q_{E D}=$ & $3386.00 \mathrm{Mio} \mathrm{KwH} / \mathrm{a}$ \\
$Q_{E I}=$ & $173.84 \mathrm{Mio} \mathrm{KwH} / \mathrm{a}$ \\
$P_{E}=$ & $51 \mathrm{TG} / \mathrm{KWh}$ \\
$Q_{C}=$ & $1.382 \mathrm{Mio}$ Short T/a \\
$l=$ & 0.694 \\
$u=$ & 0.306 \\
$D=$ & $0 \mathrm{TG}$ \\
$\rho=$ & 0.975 \\
$J=$ & $10000 \mathrm{Iterations}$ \\
$T=$ & 50 Years \\
$T_{A}=$ & 50 Years \\
$T_{C}=$ & $50 \mathrm{Years}$ \\
$I_{A}=$ & $3882.330 \mathrm{Bl} \mathrm{TG}$ \\
$C_{A}=$ & $98.246 \mathrm{Bl} \mathrm{TG}$ \\
$\pi_{A}=$ & $83.306 \mathrm{Bl} \mathrm{TG}$ \\
$N P_{A}=$ & $-1549.569 \mathrm{Bl} \mathrm{TG}$ \\
\hline
\end{tabular}

parameter values will hold constant through each scenario, providing us with distinct outputs based on the divergent price characteristics and the scenario-specific alterations.

Figures 3 and 4 show the results of running the baseline estimation model. The first point of mention is the predominantly negative value of using either the coal-based or renewablebased energy systems. The key explanation behind this phenomenon is the current energy sector price regime in Mongolia. A portion of Mongolian domestic coal industries are currently still controlled by the central government. Additionally, the energy producing sector is still predominantly operated and subsidized by the government. These factors amount to a situation where coal and energy prices are greatly depressed compared to their global equivalents.

This baseline simulation runs under the premise that the energy sector in Mongolia will be buying coal at global prices while the domestic price of electricity $\left(P_{E}\right)$ remains at the 2005 price of 51 TG per KwH (International Monetary Fund (2007)). This price is set by the Mongolia Energy Authority and is standard across all sectors including residential. For a global comparison, the average annual residential price of electricity in the United States for 
Figure 3: Options Value for Baseline Parameters - GBM

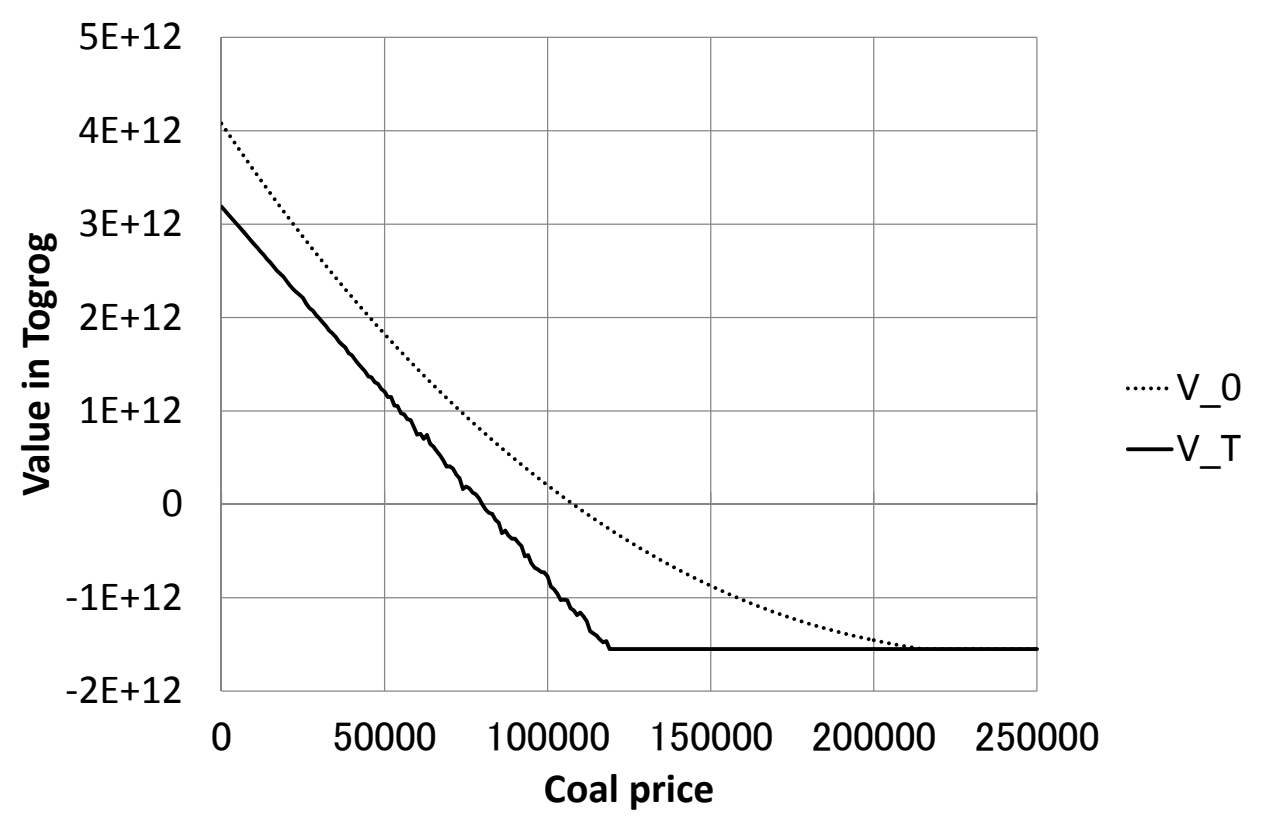

Figure 4: Options Value for Baseline Parameters - MR

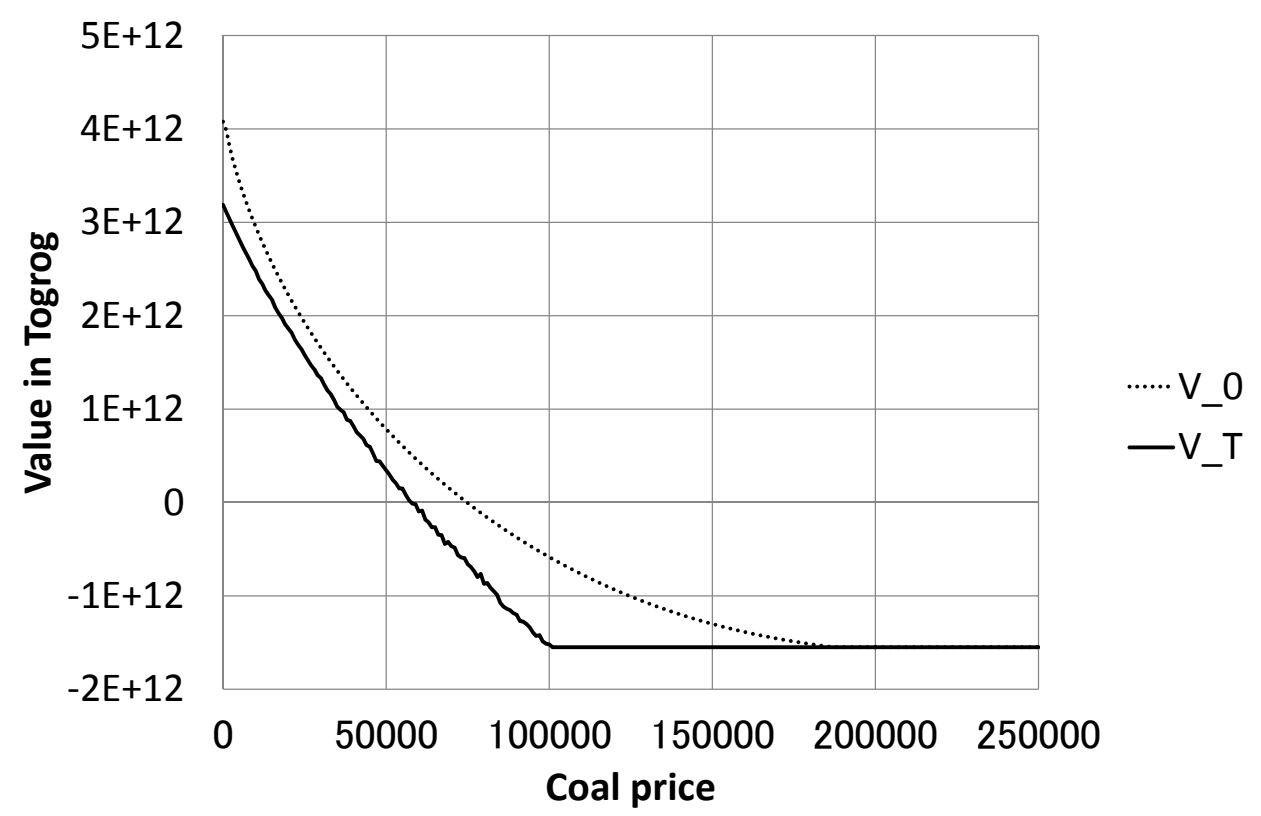


Figure 5: Coal Price Comparison

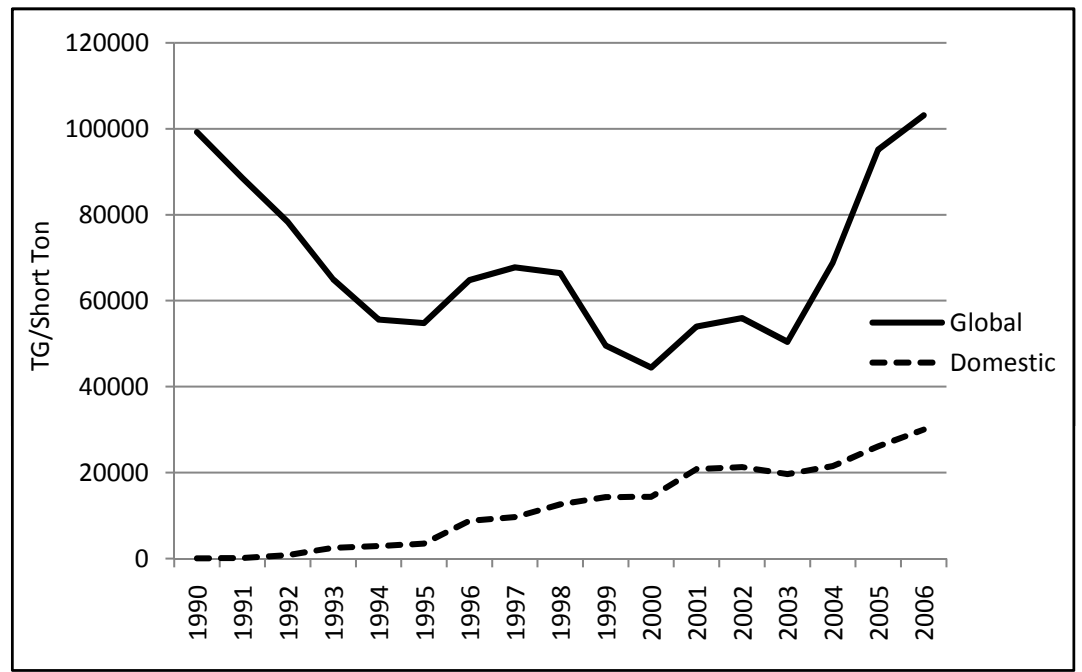

2006 was 10.4 cents per $\mathrm{KwH}$, the equivalent of 121.436 TG per KwH (Energy Information Administration (2008)). A graph of the differences between Mongolian domestic coal prices and global prices, as defined in section 2.3, from 1990 to 2006, can be seen in figure 5 .

The next point of discussion in the baseline estimations is the dynamics of the options value. The benefit of the option to wait is represented by the vertical distance between the terminal and initial period value curves. The option value diminishes with the reduction of the social revenue until reaching zero. After the revenue value crosses the horizontal axis, then the option value increases again. This is true for both the GBM and MR processes. This means that under the conditions set in this analysis, the value of waiting in a situation of price uncertainty can in some cases be less than the value of that same option the period before.

One plausible explanation for this occurrence arises from characteristics of the firm we are considering; a publicly operated enterprise, which is a necessity to society and therefore forced, in some situations, to operate at a loss. This condition, in which the value of operations is negative, results in decreasing or negative values for the option to wait until the next period to make an investment decision. Given the aforementioned feature of the option 
Figure 6: Baseline Trigger Price Dynamics

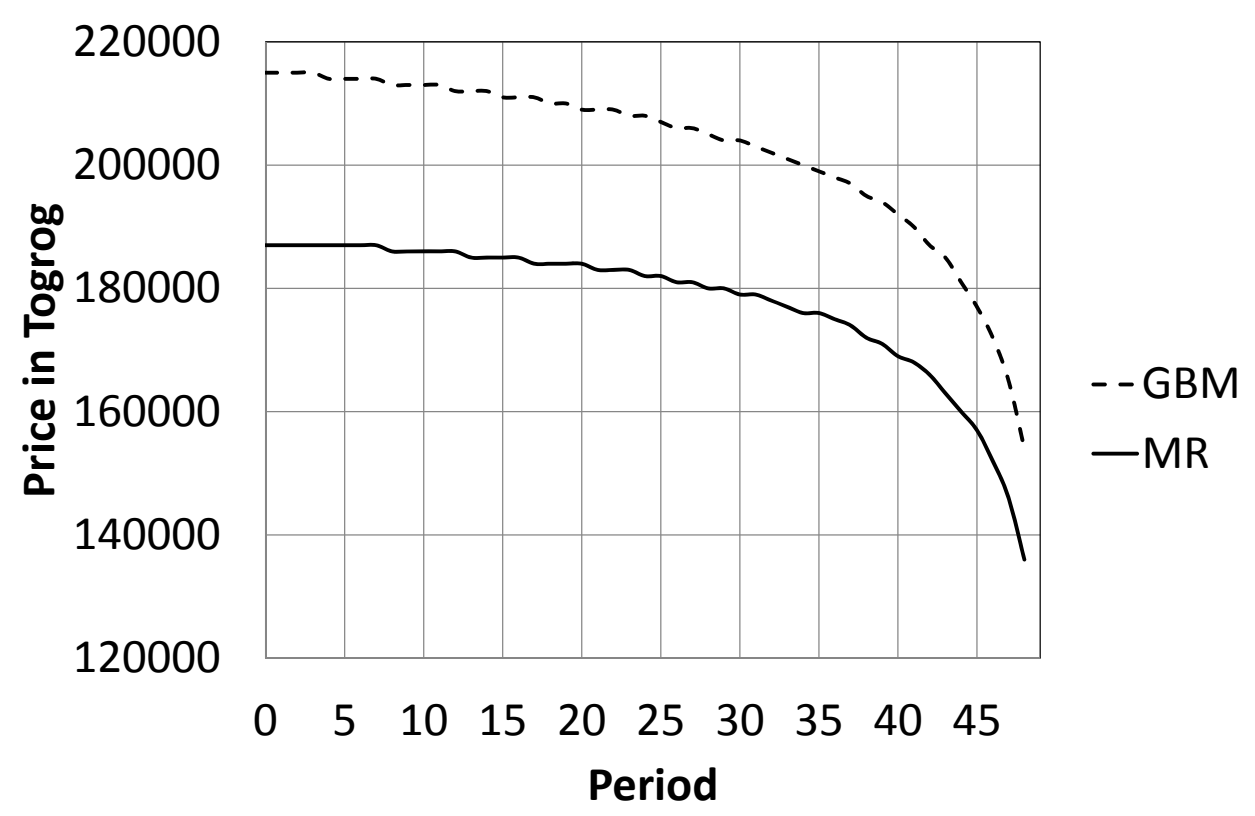

values, we have explored and identified the possibility that option values become negative, which will be presented later. The distinctions between the results obtained in this paper and existing literature are a point for further examination.

Finally, we examine the trigger prices and their dynamics over time in relation to the option values and the GBM and MR price processes (See figure 6). The trigger price is represented by the turning point in the value functions at a particular period with the value functions at the terminal period. At this price of coal, the discounted present value of the alternative energy system becomes greater than or equal to the original coal-based system. The baseline scenario trigger prices for GBM and MR are 215,000 TG and 187,000 TG at period $t=0$, respectively. From the dynamics comparison in figure 6 , we are able to see that GBM yields higher trigger prices than MR at every period of $t$, which is consistent with the results associated with option values as shown in 3 and 4 . That keeps with intuition regarding the GBM and MR processes, where the drift and uncertainty contained in GBM results in a higher option value under base cases, and thus trigger prices are higher as well. 
Table 5: Trigger Prices by Externality Level

\begin{tabular}{|lcccc|}
\hline & TG/person & D & GBM & MR \\
\hline Baseline & 0 & 0 & 215000 & 187000 \\
Run 1 & 100 & 260 & 215000 & 187000 \\
Run 2 & 500 & 1,300 & 213000 & 186000 \\
Run 3 & 1,154 & 3,000 & 173000 & 146000 \\
Run 4 & 3,269 & 8,500 & 95000 & 75000 \\
Run 5 & 50,000 & 130,000 & 32000 & 24000 \\
*Externality (D) in Mio TG & & \\
\hline
\end{tabular}

\subsection{Scenario 1: Externalities}

In this portion of the analysis, we alter the externality value to see how the trigger prices and option values in this investment environment respond to changes in the value Mongolian society places on the reduction of air pollution from burning coal, greater national and energy security, and increased availability of usable water by not having resources tied up in coalfired thermal power stations. As described in section 3.2, the externality value is arbitrarily assigned and the simulations run in this scenario include a wide range of values in order to adequately represent any number of conditions that may exist in reality.

The externality values were created under the assumption that every Mongolian resident would contribute an equal payment, therefore attempting to give an assessment of the willingness to pay by society as a whole. Using estimates for 2006 by the IMF, we set the Mongolian population at 2.6 million (International Monetary Fund (2007)). The system of externality values that we assigned in this scenario is listed in table 5, along with the corresponding trigger prices obtained in the analysis for both GBM and MR. From the table, it is evident that the overall change in amount of externality corresponds to a decrease in trigger prices, and also the trigger prices in MR are consistently lower than those in GBM.

These results follow intuition in that as Mongolian society increases the value attributed to reducing the negative externalities of a coal-based energy infrastructure, the comparative attractiveness of maintaining the system over switching to alternative energy sources 
decreases. Corresponding to these results, if each Mongolian was to pay 1,154 TG (approximately one US dollar), the trigger price would be 173000 and 146000 TG per Short Ton of coal, which significantly differ from the trigger prices under baseline scenarios.

Next, we review the effects of varying externality levels on options value. Figures 7 and 8 illustrate the dynamics of the options value as the externality is raised through a series of some simulation runs. Both the GBM and MR methods maintain the structure detailed in the baseline results, with the increasing externality forcing the curves to shift left for both the initial and terminal periods. Options values for both decline as externality value is increased and at the highest externality level, the options values are negative in MR case when $D=8500 m$ (See the dotted line in figure 8) since the two curves cross each other twice. This implies that option values are negative for some specific domain of coal prices, and this feature is confirmed especially when the value of negative externality is increased further.

This is really understandable in the sense that when the value of $D$ rises, continued operations of coal-based plants generate only negative present values and this means that the option of waiting becomes highly costly depending on the possible path of coal prices. We identify that MR cases are more likely to yield negative option values so that future evolution prices yield higher costs of holding the option to wait.

Again, note that in this analysis, externality value is not included in the net present value calculation for alternative energy since we assume that switching to alternative energy and its operation create externality free environment. Thus, it is unaffected by these changes. This is represented in the value curves shifting along the lower horizontal boundary.

\subsection{Scenario 2: Domestic electricity prices}

This scenario is developed through shifting the domestic electricity prices and examining the extenuating effects on the initial period trigger prices and the options values. As was stated in section 4.1, the baseline price for electricity in Mongolia is lower than in global 
Figure 7: Options Dynamics for Increasing Externality Value $(D)$ - GBM

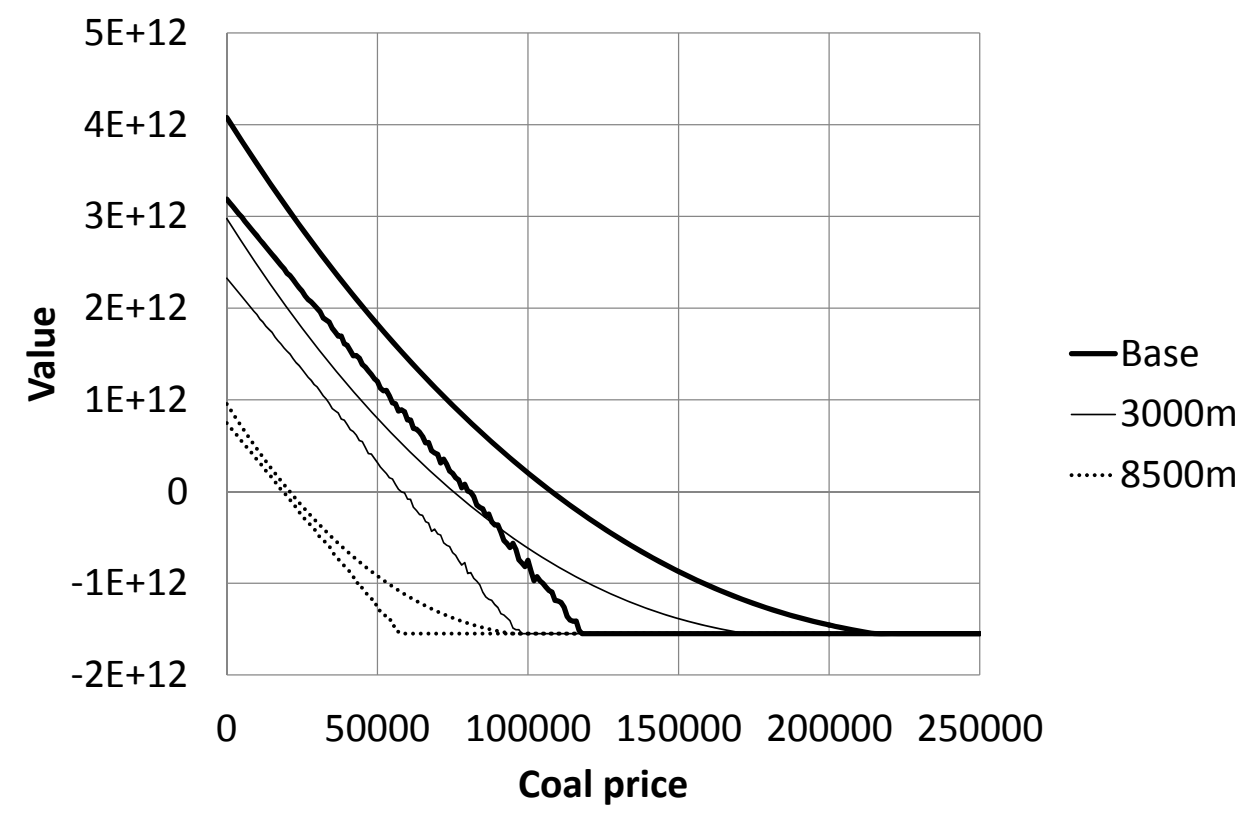

Figure 8: Options Dynamics for Increasing Externality Value $(D)$ - MR

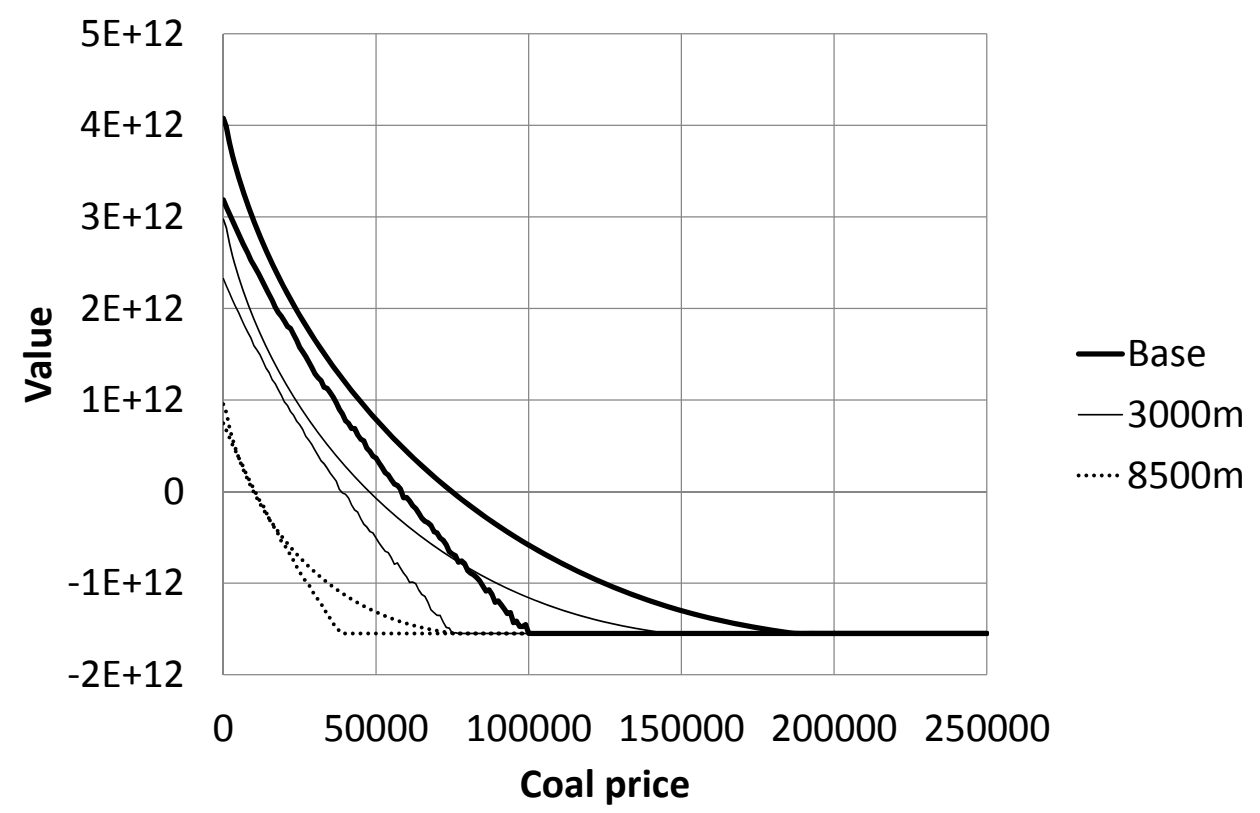


Table 6: Trigger Price by Electricity Price

\begin{tabular}{|ccc|}
\hline Pe & GBM & MR \\
\hline 30 & 229000 & 200000 \\
51 & 215000 & 187000 \\
60 & 210000 & 182000 \\
70 & 203000 & 177000 \\
80 & 197000 & 171000 \\
90 & 191000 & 166000 \\
100 & 184000 & 161000 \\
110 & 178000 & 155000 \\
120 & 172000 & 150000 \\
*In TG & & \\
\hline
\end{tabular}

price-setting markets. As a result, we decided to run simulations that can represent some plausible electricity price ranges. By changing the value widely, we are able to show the effects of potential government positions regarding future pricing strategies on electricity. These incremental step values of domestic electricity prices and their corresponding initial period trigger prices can be seen in table 6 .

The outcomes here are again in accordance with the notion of a negative relationship between electricity prices and trigger price. The electricity price parameter is included in both the coal-based and alternative energy value functions, but the coal-based function is hampered by the need to import portions of electricity at those prices as well in order to meet total domestic demand. The value function parameters for alternative energy are calculated as such that there would no longer been a need to import electricity from neighboring countries. This discrepancy between the two functions results in a greater positive effect on the value of alternative energy as electricity prices rise, lowering the initial period trigger price.

The next part of this scenario's analysis is examining the change in options value corresponding to the alterations in electricity prices. Figures 9 and 10 present the options value curves for the MR and GBM approaches. In contrast to Scenario 1, and as was explained earlier, the price of electricity is a factor in both value functions and therefore has different 
Figure 9: Options Value as Electricity Price $\left(P_{E}\right)$ Increases - GBM

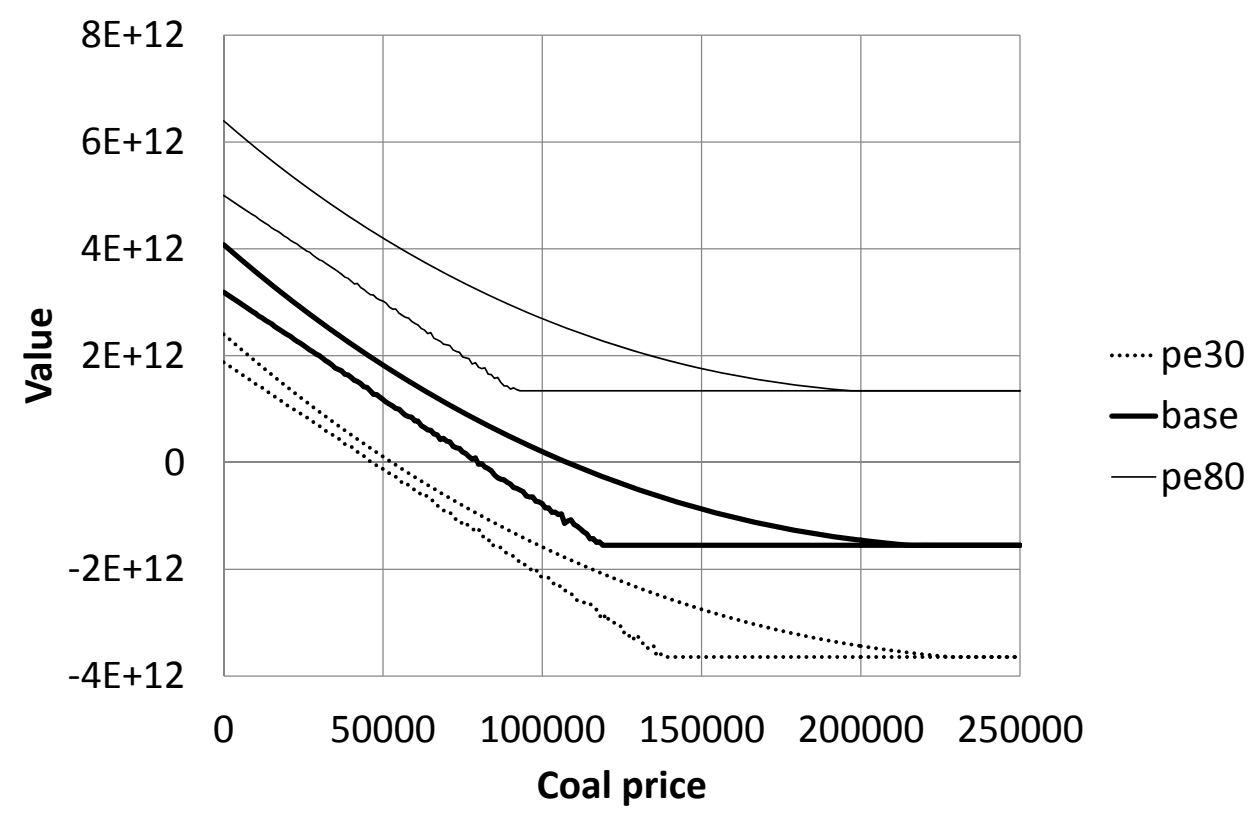

dynamics incorporated with any changes. The rise in electricity price causes the curves for both MR and GBM to shift upward and to the left, representing an increase in overall value for both the coal-based and alternative energy systems as well as a decline in trigger price.

The most significant point of mention is in regard to the assumptions made in Scenario 1 to account for the instances of decreasing or negative option values. The rise in electricity price leads to increasingly valuable situations for both the coal-based and alternative energy value functions, culminating with profitable conditions for both MR and GBM at $P_{E}=80$. On the other hand, when $P_{E}$ is set around 30, the value of investment and its corresponding option value declined at least for some domain of coal prices. In fact, we observe the same feature that options value becomes negative for $P_{E}=30$ in the MR case and the two curves cross. This implies that setting $P_{E}<51$ is not a good pricing strategy as it leads to negative investment present values and option values.

The dynamics for the options value that corresponds to these conditions develops into a pathway that could be considered the expected or typical pattern according to prevailing options theory literature. The inferences we are able to draw from this development reinforces 
Figure 10: Options Value as Electricity Price $\left(P_{E}\right)$ Increases - MR

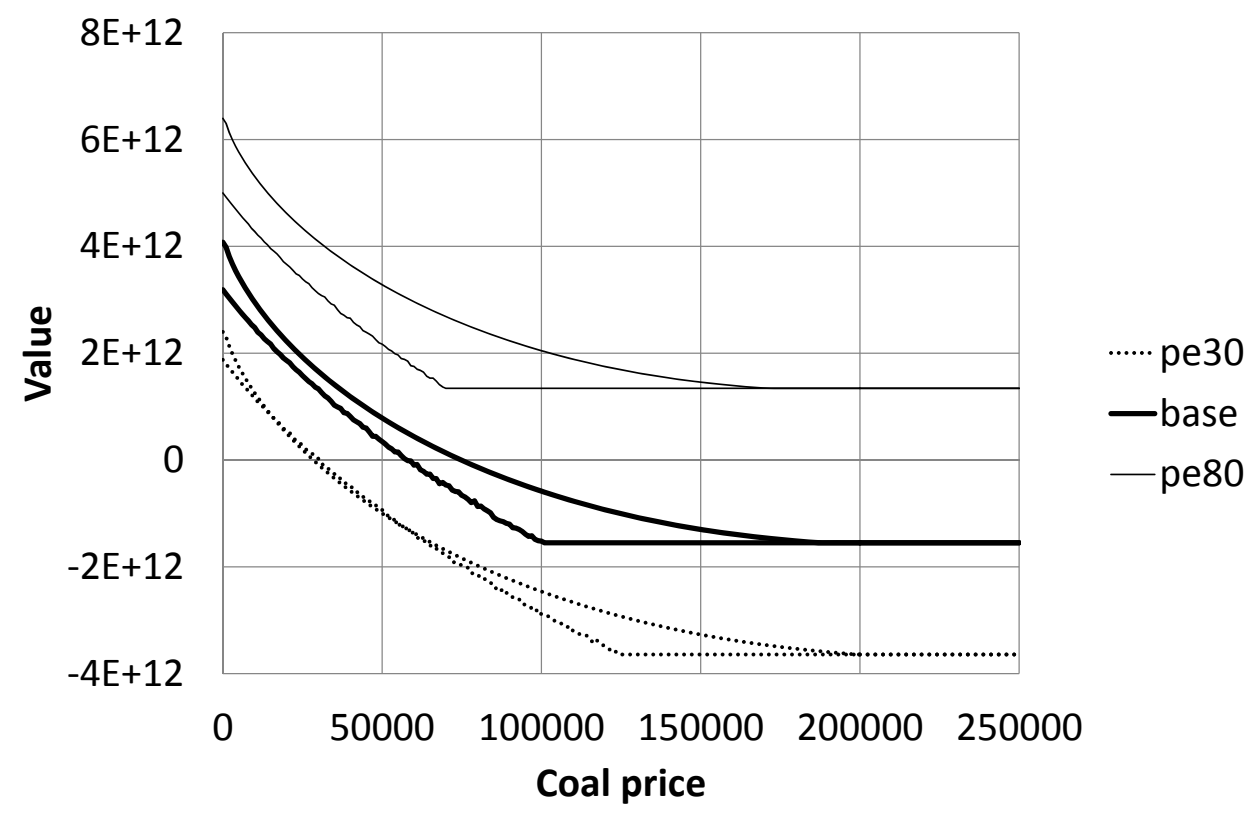

the prior assumptions made in this paper. A firm that is forced to operate under situations of negative value and profitability can have periods in the decision making process where being given the option to wait to make an investment decision may itself have a negative value, or may decrease in value from one period to the next. This type of situation can arise only in state-owned firms that provide some critical infrastructure, such as electricity generation, which is the object of our analysis. Of course, this may be unique, however, this research is the first that illustrate such a special case that option values can even be negative in such a case.

\section{Conclusions}

To represent the plausible investment environment and decision making process for switching from a coal-based energy infrastructure to a wind and solar-thermal combination energy infrastructure paradigm in developing countries, we analyzed differing price regimes and society's perceived valuing of the negative use-associated externalities of a coal-powered 
energy sector. The results of our simulations provide insights on the shifting dynamics of the optimal timing trigger prices for making the alternative energy investment by incorporating the option to wait to make the investment decision. Under situations of coal price uncertainty estimated according to prevailing real options theory literature, we found that for either an MR or GBM process, the effects of various changes in the investment environment are generally the same (Dixit and Pindyck (1994); Insley (2002)).

To examine the most realistic conditions for the decision making process in Mongolia, the proxy for heavily coal-dependent developing countries, we assumed that each Mongolian resident would be willing to pay some money for the removal or reduction of air pollution resulting from burning coal, greater national and energy security, and increased availability of usable water by not having resources tied up in coal-fired thermal power stations. Additionally, in predicting that Mongolian domestic coal prices will eventually reach regionally competitive prices, there is a resulting need to increase the price of electricity domestically in order to create a profitable operating environment for the energy sector. Setting the domestic electricity price to between 60 and $120 \mathrm{TG}$ per $\mathrm{KwH}$ would enable the energy sector to operate in more profitable conditions while still requiring the marginal Mongolian to pay a lower hourly rate than major global price-setting nations. The inclusion of an externality value and raising electricity prices provided for a much lower optimal timing trigger price, where the alternative energy option becomes more valuable than continuing to operate with a coal-based system.

Dynamically optimizing the above processes provides a number of recommendations for decision makers in the Mongolian energy sector to consider. As the price of coal in Mongolia rises to regionally competitive levels through the privatization of nationally operated coal industries or globalization of domestic coal markets, either the price of electricity will need to be increased or the cost of coal inputs for the energy sector will need to be further subsidized. Raising electricity prices increases the attractiveness of alternative energy investments, which itself has additional value through the reduction of negative externalities. If Mongolian 
society highly values cleaner air, greater energy and national security, and more usable water, then both the decision to raise electricity prices and shift to a greater reliance on alternative energy resources is the ideal paradigm. At current regional coal prices, a balance of increased electricity prices and externality valuation results in an investment environment that favors the wind and solar-thermal energy infrastructure applied in this research.

It is our belief that the series of analysis and conclusions made in this research provides furhter insights on more general cases of energy switch in other developing nations as well. In the recent years, many developing nations face the similar problem in term of the way how they ensure stable energy supply as well as tackle environmental issues such as the mitigation of pollution. Therefore, they consider energy switch from non-renewable sources as an option. Reflecting this on-going issue, our research is the first that formalizes and analyzes this problem as a type of real option, as well as raises the potential risks and countermeasures of the investment opportunities from nonrenewable to renewable energy in general that can be seen all over the world.

\section{References}

Bertsekas, D. P. (2001). Dynamic programming and optimal control. Athena scientific.

Bosetti, V., Conrad, J. M., and Messina, E. (2004). The value of flexibility: Preservation, remediation, or development for Ginostra. Environmental and resource economics, 29:219229.

Boyarchenko, S. and Levendorskii, S. (2007). Practical guide to real options in discrete time. International economic review, 48(1):311-342.

Brown, R. (2008). Privatization of the Mongolian coal and energy sectors. Ulaanbaatar, Mongolia. Interview by Neal C. Detert (Jan. 12, 15, 20, 2008).

DATAMONITOR (2007). Global energy: Industry profile. Sydney: DATAMONITOR.

Dixit, A. K. and Pindyck, R. S. (1994). Investment under Uncertaity. Princeton University Press.

Economist Intelligence Unit (2007). Country profile 200\%: Mongolia. London: Patersons Dartford.

Ellerman, D. (1995). The world price of coal. Energy policy, 23(6):499-506. 
Elliot, D., Schwartz, M., Scott, G., Haymes, S., Heilmiller, D., and George, R. (2001). Wind Energy Resource Atlas of Mongolia. Springfield: National Renewable Energy Laboratory.

Enders, W. (2004). Applied econometric time series. Wiley, 2 edition.

Enebish, N. (2004). Renewable Energy Application in Mongolia. Manila, Philippines: Asian Development Bank.

Energy Information Administration (2008). Average Retail Price of Electricity to Ultimate Customers by End-Use Sector. Energy Information Administration: Official Energy Statistics from the US Government Website, http://www.eia.doe.gov/cneaf/electricity/epa/epat7p4.html(accessed March 24, 2008).

Haight, R. G. and Holmes, T. P. (1991). Stochastic price model and optimal tree cutting: Results for loblolly pine. Natural resource modeling, 5(4):1-21.

Insley, M. (2002). A real options approach to the valuation of a forest investment. Journal of environmental economics and management, 44:471-492.

International Monetary Fund (2002). IMF country report 02/253 Mongolia selected issues and statistical annex. Washington, D.C.: International Monetary Fund.

International Monetary Fund (2007). IMF country report 0\%/39 Mongolia selected issues and statistical annex. Washington, D.C.: International Monetary Fund.

Japanese Statistic Bureau (2008). Japanese import data by country and commodity. Tokyo: Ministry of Internal Affairs and Communications.

Judd, K. L. (1998). Numerical methods in economics. MIT Press.

Kaltzchmitt, M., Streicher, W., and Wiese, A. (2007). Renewable energy: Technology, economics and environment. Springer.

Metcalf, G. E. and Hasset, K. A. (1995). Investment under alternative return assumptions, comparing random walks and mean reversion. Journal of economic dynamics and control, 19:1471-1488.

Mongolian Energy Authority (2006). Statistical information for the Mongolian energy sector. Ulaanbaatar: Mongolian Energy Authority.

Plantinga, A. J. (1998). The optimal timber rotation: An option value approach. Forest Science, 44(2):192-202.

Puterman, M. L. (1994). Markov decision processes, discrete stochastic dynamic programming. John Wiley \& Sons, Inc.

Schwartz, E. S. and Trigeorgis, L. (2004). Real options and investment under uncertainty: Classical readings and recent contributions. MIT Press. 
Sheer, H. (2007). Energy autonomy: The economic, social and technological case for renewable energy. Earthscan.

Smith, J. E. and McCardle, K. F. (1999). Options in the real world: Lessons learned in evaluating oil and gas investments. Operations research, 47(1):1-15.

Warell, L. (2005). Defining geographic coal markets using price data and shipments data. Energy policy, 33:2216-2230.

World Coal Institute (2005). The coal resource: A comprehensive overview of coal. World Coal Institute Website, http://www.worldcoal.org (accessed Feb. 12th, 2008). 